\title{
86 CROSS SECTIONAL SURVEY ON ADVANCE CARE PLANNING ACCEPTANCE AND END OF LIFE CARE PREFERENCES AMONG COMMUNITY DWELLING ELDERLY WITH COMPLEX MEDICAL PROBLEMS AND THEIR CARERS
}

M L Tsang, ${ }^{1}$ K M Yeung, ${ }^{2}$ Kenny Wong, ${ }^{3}$ P T Lam ${ }^{4}{ }^{1}$ Wong Tai Sin Hospital, Hong Kong, China; ${ }^{2}$ Princess Margaret Hospital, Hong Kong China; ${ }^{3}$ Tuen Mun Hospital, Hong Kong, China; ${ }^{4}$ United Christian Hospital, Hong Kong

\subsection{6/bmjspcare-2013-000491.86}

Background Advance care planning is a useful tool to facilitate families and healthcare providers to understand patient's value system, and to make decision on patient's behalf on the care that considered appropriate when one cannot make decisions.

Advanced Directive (AD), has been in place in HK for more than 10 years, is one of the means to address advance care planning. Two local studies were done among institutionalised older persons on their

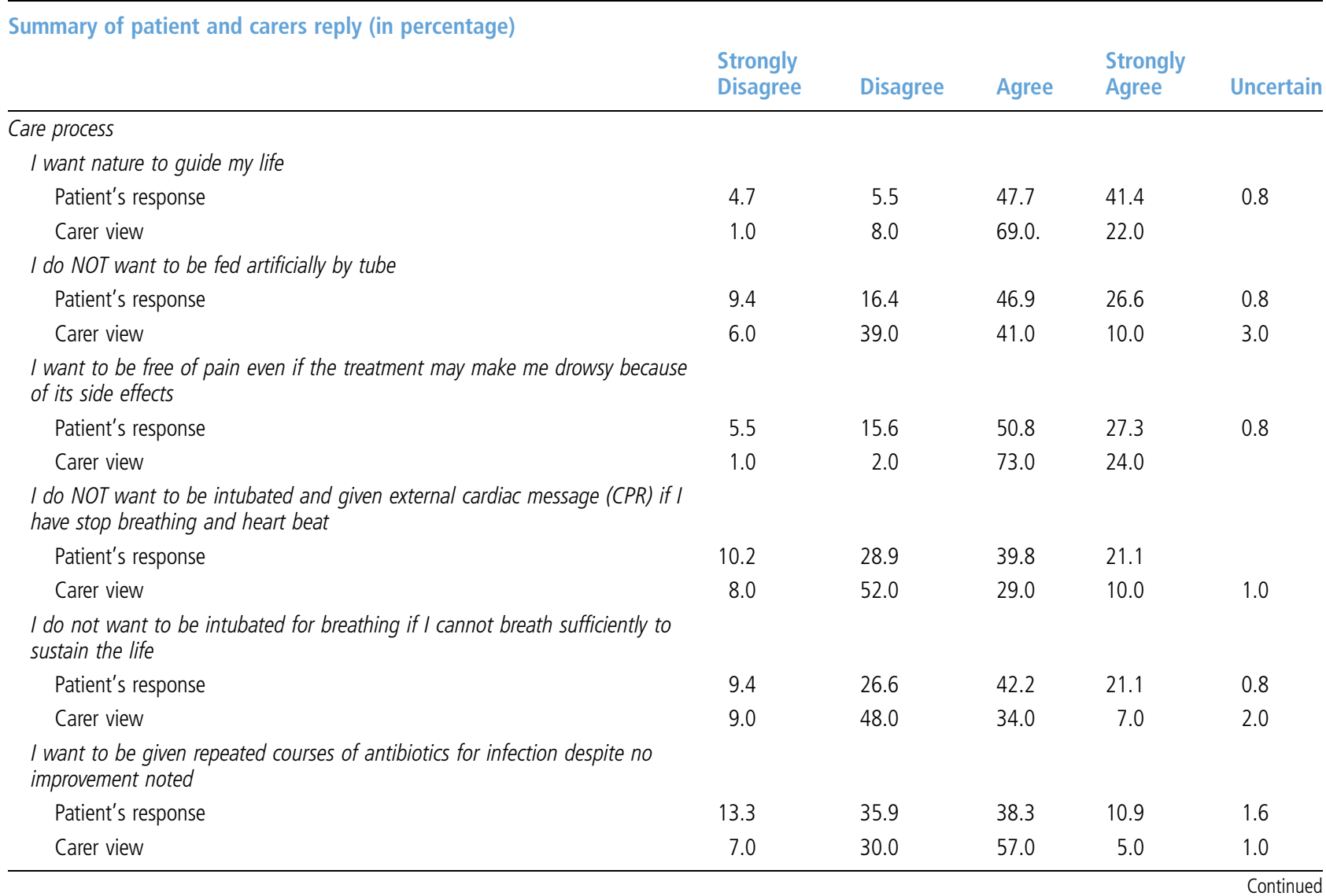




\begin{tabular}{|c|c|c|c|c|c|}
\hline & $\begin{array}{l}\text { Strongly } \\
\text { Disagree }\end{array}$ & Disagree & Agree & $\begin{array}{l}\text { Strongly } \\
\text { Agree }\end{array}$ & Uncertain \\
\hline \multicolumn{6}{|l|}{ Decision making process } \\
\hline \multicolumn{6}{|c|}{ I want my doctor(s) to make all decisions } \\
\hline Patient's response & 2.3 & 13.3 & 53.9 & 29.7 & \multirow[t]{2}{*}{0.8} \\
\hline Carer view & 8.0 & 17.0 & 60.0 & 15.0 & \\
\hline \multicolumn{6}{|c|}{ I want my family to make all decisions for me } \\
\hline Patient's response & 10.9 & 35.9 & 46.1 & 6.3 & \multirow[t]{2}{*}{0.8} \\
\hline Carer view & 6.0 & 53.0 & 38.0 & 3.0 & \\
\hline \multicolumn{6}{|c|}{ I want to make decision by myself } \\
\hline Patient's response & 4.7 & 22.7 & 53.9 & 18.0 & \multirow[t]{2}{*}{0.8} \\
\hline Carer view & 2.0 & 29.0 & 58.0 & 11.0 & \\
\hline \multicolumn{6}{|c|}{ I want to make conjoint decision with my family } \\
\hline Patient's response & 4.7 & 26.6 & 53.1 & 15.6 & \\
\hline Carer view & 3.0 & 16.0 & 57.0 & 24.0 & \\
\hline
\end{tabular}

Respond to hypothetical conditions

1) I have dementia and currently need major assistance in self care, cannot verbally communicate and eats very little/does not eat. I prefer:

patient care
7.0

to be fed by a tube that needs to be changed every 1-4 weeks, and my hands may need to be tied to prevent me from pulling it

to continue with small oral feed even if I may progressive lost weight and weaker

2) I have chronic lung disease and have shortness of breath even with feeding. To reduce the shortness of breath, I prefer

to use a ventilator through face mask all day even if you pulled it off yourself when medical team had used it to rescue you

to use oral medication even if there may have possible risks/side effects that make me drowsy

3) I have chronic lung disease and have shortness of breath even with feeding. To reduce the shortness of breath, I prefer

to use a ventilator through face mask all day even if you pulled it off yourself when medical team had used it to rescue you

to use oral medication even if there may have possible risks/side effects that make me drowsy

preference on $\mathrm{AD}$. Little is known on the preference among non-institutionalised older persons.

Aim Primary objective is estimate preference of advance care planning acceptance among community dwelling older persons with multiple medical problems. Secondary objectives are : to estimate end of life care preference as listed and potential factors affecting their choices; whether there is difference in view of older person's choice in comparisons to their next-of-kid

Methods A Multi-centre, cross sectional survey using a structured, interviewer administered questionnaire.

Older persons with age $>6$, fulfilling the inclusion criteria, who attend Geriatric out-patient clinic or Day Hospital in the study period, and their paired next-of-kin are invited to participate.

Results 4 out of 7 centres have preliminary results available (see table)

Discussion High acceptance of advance care planning in the interviewed patient (78\%) and carers (79\%).

Marked difference in views are observed in artificial feeding, pain management and use of antibiotic.

Conclusion Further analysis to address the difference observed is planned. Territory wide public education and promotion on advance care planning is needed. 